\title{
Cooperação judiciária internacional entre países lusófonos em matéria probatória civil e comercial - estado da arte e perspectiva futura
}

https://doi.org/10.21814/uminho.ed.30.18

\author{
Lurdes Varregoso Mesquita \\ Doutora em Direito \\ Professora Auxiliar do Departamento de Direito da Universidade Portucalense \\ Professora Adjunta do Instituto Politécnico do Porto \\ Investigadora do Instituto Jurídico Portucalense
}

\section{Nota introdutória}

A prova é um elemento fundamental no processo. Tomada na acepção de actividade processual adstrita aos fins da instrução, a prova tem por função a demonstração da realidade dos factos, como decorre do artigo $341 .^{\circ}$ do Código Civil ${ }^{1}$. Qualquer alegação factual ficará esvaziada se não for provada.

Assim, o direito à prova, ou seja, o direito à apresentação das provas que visam demonstrar a realidade dos factos alegados em juízo, constitui um direito fundamental integrado no due process ou processo equitativo. Este imperativo constitucional consagra o direito fundamental de acesso ao direito e à tutela jurisdicional efectiva, onde se inclui o direito de acção ou direito de agir em juízo. Por sua vez, o direito de acção efectiva-se através de um processo equitativo que inclui várias vertentes, entre elas o direito à prova ${ }^{2}$ (art. $20 .^{\circ}$, n. $^{\circ} 4$, da Constituição da República Portuguesa).

A litigância internacional não é um fenómeno recente mas vem ganhando cada vez mais importância no mundo globalizado onde proliferam as relações jurídicas plurilocalizadas, que provocam a necessidade de obtenção de provas no estrangeiro. Neste contexto, o presente estudo pretende fazer uma breve incursão pelos meios de obtenção de prova no estrangeiro, conforme os respectivos modelos adoptados, referindo o regime interno, de carácter supletivo, e o regime europeu, onde a matéria está mais desenvolvida. No âmbito dos Países de Língua Portuguesa, mostra-se o estado da arte da cooperação judiciária em matéria de prova, olhando para a

1 Doravante designado, abreviadamente, CC.

2 Sobre as vertentes do princípio do processo equitativo, ver CANOTILHO, José Joaquim Gomes; Vital MOREIRA; Constituição da República Portuguesa Anotada, Volume I - Artigos $1^{\circ}$ a $107^{\circ}, 4^{\text {a }}$ edição Coimbra Editora, Coimbra, 2007, pp. 406-419. 
perspectiva futura, resultante da criação da Rede de Cooperação Jurídica e Judiciária Internacional dos Países de Língua Portuguesa.

\section{Obtenção de prova no estrangeiro à luz da lei processual civil}

\subsection{Contexto e regime geral}

Não é rara a necessidade de instruir um processo com elementos de prova cuja obtenção tem de ser efectuada fora da área de jurisdição dos tribunais portugueses. O exemplo mais comum está relacionado com a tomada de declarações de testemunhas que residem no estrangeiro ou de depoimento de parte, mas há outros casos, como por exemplo: colheita de material genético ou amostras de sangue para análise de DNA; informação ou relatório sobre a situação económica e social de uma pessoa; localização da situação dos bens de uma pessoa; localização do paradeiro de uma pessoa; obtenção de documentos que certifiquem factos, a situação legal de uma pessoa ou de um bem, emitidos por entidades públicas do Estado requerido (ex.: situação registral, estabelecimento da paternidade).

A lei processual civil consagra um regime geral de obtenção de provas no estrangeiro e disciplina os pedidos de realização de actos probatórios no Estado de destino, assim como o recebimento desses pedidos em Portugal. Esse regime tem carácter supletivo e tem aplicação apenas nas situações não abrangidas por regulamento europeu, tratado ou convenção que disponha em contrário.

Vigora, assim, o método clássico de «formas de requisição e comunicação de actos» através de carta precatória e de carta rogatória, consagrado no art. $173 .^{\circ}$, n. $^{\circ} 1$, do $\mathrm{CPC}^{3}$. A distinção assenta na qualidade do destinatário. É usada a carta precatória quando se solicita a realização do acto a um tribunal ou a um cônsul português e a carta rogatória quando a solicitação é feita a uma autoridade estrangeira.

Quanto ao modo de expedição, de acordo com o art. $177 .^{\circ}$ do CPC, está prevista a regra da expedição directa à entidade ou tribunal estrangeiro. Regra essa que será afastada quando: i) o Estado em causa impuser a via diplomática ou consular como via de comunicação, caso em que a carta é entregue ao Ministério Público para que siga pelas vias competentes - que pode ser um longo percurso: Procuradoria Geral da República/Ministério da Justiça/Ministério dos Negócios Estrangeiros/Embaixada de Portugal no Estado rogado/Ministério dos Negócios Estrangeiros do Estado rogado/Ministério da Justiça/Tribunal do destino; ii) o Estado respectivo não receba

3 As normas sobre a comunicação dos actos são instrumentais à matéria probatória, porquanto auxiliam, facilitam e/ou permitem a produção da prova fora do tribunal em que corre termos a causa. No ordenamento português, são os arts. $172 .^{\circ}$ a $185 .^{\circ}$ do CPC que disciplinam a comunicação dos actos. Sobre esta matéria, consultar as respectivas anotações aos artigos em: FREITAS, José Lebre de; ALEXANDRE, Isabel; Código de Processo Civil Anotado, Volume $1^{\circ}$ - Artigos $1^{\circ}$ a $361^{\circ}, 3 .^{a}$ edição, Coimbra: Coimbra Editora, 2014; GERALDES, António Santos Abrantes; PIMENTA, Paulo; SOUSA, Luís Filipe Pires de; Código de Processo Civil Anotado, Volume I - Artigos $1^{\circ}$ a $702^{\circ}$, Coimbra: Almedina, 2018. 
cartas por via oficial, circunstância em que estas são entregues ao interessado, em modelo que não permita duvidar da sua autenticidade.

\subsection{Portugal enquanto Estado rogado}

Não havendo fundamento para a recusa legítima, o Estado português cumpre a carta rogatória e realiza o acto rogado de acordo com a lei processual interna (art. 182. ${ }^{\circ}$, do (PC). São motivos de recusa: incompetência para o ato requisitado; proibição absoluta do acto rogado; a carta não estar legalizada, salvo se houver sido recebida por via diplomática ou se houver tratado, convenção ou acordo que dispense a legalização; o acto ser contrário à ordem pública portuguesa; a execução da carta ser atentatória da soberania ou da segurança do Estado; o acto importar execução de decisão de tribunal estrangeiro sujeita a revisão e que se não mostre revista e confirmada (cfr. arts. $179 .^{\circ}$ e $180 .^{\circ}$, do CPC).

Quanto ao regime de recebimento, o Estado português aceita qualquer das vias, seja a via directa (de tribunal a tribunal), a via particular ou a via diplomática ou consular (art. 181. ${ }^{\circ}$, n. ${ }^{\circ}$, do CPC). Recebida a carta rogatória, o juiz decide sobre o seu cumprimento, após visto do Ministério Público, a quem compete pronunciar-se sobre o cumprimento, podendo opor-se por razões de interesse público. É ao Ministério Público que compete promover os termos das cartas que hajam sido recebidas por via diplomática (art. 181. ${ }^{\circ}$, n. $^{\circ}$ 2, do CPC).

\section{Obtenção de prova no espaço europeu de justiça ao abrigo da legislação europeia}

A cooperação entre os tribunais dos Estados-Membros da União Europeia, no que diz respeito à obtenção de provas em matéria civil ou comercial, encontra-se disciplinada no Regulamento 1206/2001, de 28 de Maio de 20014. Nesta matéria, deve ainda ser considerado o Regulamento 4/2009, de 18 de Dezembro de 2008, relativo à competência, à lei aplicável, ao reconhecimento e à execução das decisões e à cooperação em matéria de obrigações alimentares, onde se prevê, nas funções específicas das autoridades centrais:- ajudar a obter provas documentais ou outras, sem prejuízo do Regulamento 1206/2001; - prestar assistência para determinar a filiação, se tal for necessário (art. 51. ${ }^{\circ}$ do Regulamento 4/2009). Em processos de regulação, alteração ou incumprimento de responsabilidades parentais ou em processos de promoção dos direitos de protecção das crianças, pode ser obtida prova da situação laboral, económica e social do pai ou da mãe que resida no estrangeiro, através de pedido formulado à Divisão de Cooperação Judiciária Internacional da Direcção Geral da Administração da Justiça.

À luz do Regulamento 1206/2001 e de acordo com o seu artigo 1. ${ }^{\circ}$, a obtenção de provas entre os Estados-Membros pode dar-se por uma de duas modalidades,

4 JO L 174/1 de 27.6.2001. Aplicável aos Estados-Membros da União Europeia, com excepção da Dinamarca. 
a saber: i) obtenção de provas através do tribunal requerido (arts. $10^{\circ}$ a $\left.16 .^{\circ}\right)$; e, ii) obtenção direta de provas pelo tribunal requerente (art. 17. $\left.{ }^{\circ}\right)^{5}$. Neste caso, o tribunal requerente pretende realizar directamente o acto probatório. Na primeira modalidade, o responsável pelo procedimento de obtenção de provas é o tribunal requerido; enquanto que na segunda modalidade é o próprio tribunal requerente, havendo de obter autorização do Estado-Membro onde as provas serão obtidas. Esta diferença não exclui a possibilidade de o tribunal que não tenha a responsabilidade de obter as provas poder participar nas diligências (cfr. arts. $12 .^{\circ}$ e $17 .^{\circ}$, n. $\left.^{\circ} 4\right)$. Além disso, na produção da prova, por exemplo testemunhal, esta pode ser obtida por intermédio de meios técnicos locais e à distância, sendo incentivado o uso da videoconferência (arts. $10 .^{\circ}$, n. ${ }^{\circ} 4$ e $17 .^{\circ},{ }^{\circ}{ }^{\circ} 4$ ).

Para a eficácia da obtenção de prova noutro Estado-Membro é disponibilizado um conjunto de informações no Portal Europeu de Justiça que auxilia as autoridades no recurso a este regime e que serve a articulação do Regulamento 1206/2001 com o ordenamento interno. No caso português, foram prestadas as informações seguintes: as autoridades competentes para efeitos do art. $2 .^{\circ}$ do Regulamento (tribunal requerido) são os tribunais de comarca (tribunais de $1 .^{a}$ instância); a entidade central para efeitos do art. 3. ${ }^{\circ}$ do Regulamento é a Direcção Geral da Administração da Justiça, onde existe uma Direcção de Serviços Jurídicos e Cooperação Judiciária Internacional e uma Divisão de Cooperação Judiciária Internacional ${ }^{6}$; as línguas que podem ser utilizadas para o preenchimento dos formulários, para efeitos do art. $5 .^{\circ}$ do Regulamento são o português ou o espanhol; para efeitos do art. $6 .^{\circ}$ do Regulamento, os meios aceites para a transmissão dos pedidos e outras comunicações são: como meios de recepção de pedidos e outras comunicações são aceites a via postal, a telecópia e os meios telemáticos; em casos urgentes, pode utiliza-se o telegrama, a comunicação telefónica (seguida de documento escrito) ou outro meio análogo de comunicações; para efeitos do art. 17..$^{\circ}$ do Regulamento, para apreciação dos pedidos de obtenção directa de provas é competente a Entidade Central, isto é, a Direcção Geral da Administração da Justiça; nos termos do art. $21^{\circ}$, n. ${ }^{\circ} 2$ do Regulamento, Portugal comunicou o Acordo entre a República Portuguesa e o Reino de Espanha relativo à Cooperação Judiciária em Matéria Penal e Civil', como sendo um Acordo destinado a facilitar mais a obtenção de provas, compatível com o Regulamento.

Nesta matéria, a União Europeia está em processo de evolução. A partir de 1 de julho de 2022, o Regulamento 1206/2001 é revogado e substituído pelo Regulamento

5 Sobre a matéria da obtenção de provas entre os Estados-Membros, ver MARINHO, Carlos M. G. de Melo - Textos de Cooperação judiciária Europeia em Matéria Civil e Comercial, Coimbra: Coimbra Editora, pp. 7-47. VILLAMARÍN LÓPEZ, María Luisa - Obtención de pruebas en otros Estados de la Unión Europea, in LA OLIVA SANTOS, Andrés de (Dir.); CALDERÓN CUADRADO, Maria Pía (Coord.); “Derecho Procesal Civil Europeo -Acceso a la Justicia y Auxilio Judicial en la Unión Europea”, , Volume II, Navarra: Editorial Aranzadi, 2011, pp. 297-365. Ver, ainda, Guia Prático sobre a Aplicação do Regulamento Relativo à Obtenção de Provas, elaborado pela Comissão Europeia e disponível em https://e-justice.europa.eu/content_ejn_s_publications-287-pt.do?init=true .

6 Consultar: http://www.cji-dgaj.mj.pt.

7 Cfr. DL 14/98, de 27 de Maio, Aviso 274/98 e Listagem n. ${ }^{0}$ 73/2000. 
2020/1783, de 25 de novembro ${ }^{8}$, através do qual a União Europeia visa simplificar e racionalizar os procedimentos de obtenção de provas. Pretende-se que os pedidos sejam feitos em formulários próprios e remetidos electronicamente e de forma directa, através de plataformas seguras e interoperáveis (por exemplo, ao abrigo do projecto e-(odex ${ }^{9}$ ). Além disso, a utilização dos meios tecnológicos são privilegiados na obtenção direta de prova, que deverá ser realizada por videoconferência ou por meio de outra tecnologia de comunicação à distância. $O$ novo Regulamento dedica a esta questão os Considerandos 21, 22 e 23, assim como introduz uma disposição própria (o art. 20. ${ }^{\circ}$ ) sobre a mesma, onde estipula que "[s]e a produção de prova consistir na audição de uma pessoa presente noutro Estado-Membro e o tribunal requerer a obtenção direta de prova, nos termos do artigo $19 .^{\circ}$, esse tribunal obtém as provas por videoconferência ou por meio de outra tecnologia de comunicação à distância, desde que essa tecnologia esteja à disposição do tribunal e este considere adequado utilizar tal tecnologia em função das circunstâncias do caso".

\section{Obtenção de prova noutros Estados}

À escala mundial, a Convenção de Haia sobre a Obtenção de Provas no Estrangeiro em Matéria Civil ou Comercial, concluída em 18 de Março de $1970^{10}$, é o instrumento que suporta esta matéria ${ }^{11}$ e também prevalece sobre o que dispõe a lei interna. Por aplicação da Convenção, os pedidos instrutórios seguem, à semelhança do que se encontra previsto na legislação de processo, por via de carta rogatória remetida às entidades centrais, podendo também haver comunicações por via consular ou diplomática. No caso português, a entidade central é igualmente a Direcção Geral da Administração da Justiça. Noutras informações, Portugal declara aceitar apenas a língua portuguesa e admite a videoconferência.

Internamente, já foi implementada a tramitação electrónica dos Processos de Cooperação Judiciária Internacional em Matéria Civil e Comercial. Por Ofício Circular 4/2017 [DSJCI/DCJI de 13 de Fevereiro de 2017] foram eliminadas, definitivamente, as comunicações em suporte de papel, usadas só a título excepcional. A comunicação entre os tribunais e a Direcção Geral da Administração da Justiça é feita utilizando apenas suporte electrónico, o que demonstra um progresso e uma intenção de harmonização entre processos internos e processos transfronteiriços.

8 JO L 405 de 2.12.2020, pp. 1-39.

90 art. $7^{\circ}$, n. ${ }^{\circ} 1$, do novo Regulamento, determina que "[o]s pedidos apresentados e comunicações feitas nos termos do presente regulamento são transmitidos por meio de um sistema informático seguro, fiável e descentralizado, no pleno respeito dos direitos e das liberdades fundamentais. Esse sistema informático descentralizado deve ter por base uma solução interoperável, como o e-CODEX".

10 Aprovada pelo Estado português através do Decreto Lei n. ${ }^{\circ}$ 764/74, de 30 de Dezembro.

11 Sobre este instrumento, ver ÁLVAREZ GONZÁLEZ, S., La Cooperación Judicial Internacional en Matéria Civil, "Dereito", 2001, pp. 7 e ss. (concretamente pp. 25 a 29). 


\section{O caso especial do espaço lusófono}

Portugal, além da sua dimensão europeia, tem uma dimensão lusófona que o liga, intimamente, aos países de língua oficial portuguesa, com os quais mantém relações fortes e que se pretendem frutíferas, nas suas várias vertentes. Nessa medida, a cooperação judiciária é um suporte essencial nas relações entre os vários Estados da Comunidade dos Países de Língua Portuguesa (CPLP). Essa consciência levou a que, no fim de 2005, a “Conferência de Ministros dos Países de Língua Portuguesa” tomasse a iniciativa de criar uma Rede de Cooperação Jurídica e Judiciária Internacional dos Países de Língua Portuguesa ${ }^{12}$. Com este projecto pretende-se, à semelhança da União Europeia, criar uma rede de pontos de contacto para a cooperação jurídica e judiciária internacional (quer na área penal, quer na área civil) entre os países lusófonos.

A mais recente iniciativa, neste âmbito, foi a criação do Atlas Judiciário Lusófono ${ }^{13}$, onde se presta informação em todas as áreas de cooperação judiciária e através do qual se identificam as autoridades competentes para receber e executar um pedido de cooperação judiciária internacional. 0 portal já dispõe de muito material de apoio aos profissionais e às entidades cooperantes, permitindo identificar qual o instrumento legal aplicável à cooperação, por área de actuação, e disponibilizando o texto legal e os formulários necessários aos pedidos, seja de citação, notificação ou obtenção de prova.

As relações de cooperação judiciária entre os vários países lusófonos assentam em acordos bilaterais ${ }^{14}$ ou, no caso do Brasil, na convenção de Haia. $\mathrm{O}$ mais recente e mais avançado instrumento é o Acordo com Cabo Verde, aprovado pela resolução da Assembleia da República n. ${ }^{\circ}$ 6/2005, de 9 de dezembro de $2004^{15}$. Neste já existe a designação de uma entidade central (Direcção Geral da Administração da Justiça em Portugal e Procuradoria-Geral da República em Cabo Verde) e as cartas rogatórias são feitas com base em formulários próprios. E está prevista a inquirição por teleconferência sempre que existam os meios técnicos necessários (art. 17. ${ }^{\circ}$, do referido Acordo).

No geral, os intervenientes na relação de cooperação são os mesmos: Tribunal Requerente e Tribunal Requerido; Agentes Diplomáticos e Consulares; Autoridades Centrais (formalmente definida apenas no caso de Cabo Verde). Todos os Acordos bilaterais admitem a remessa directa de cartas rogatórias pelo Tribunal de um dos

12 Criada através de instrumento aprovado na Praia, em de Novembro de 2005. Composta por Angola, Brasil, Cabo Verde, Guiné Bissau, Moçambique, Portugal, São Tomé e Príncipe e Timor Leste.

13 Disponível em https://www.atlascplp.csm.org.pt/.

14 Designadamente: Acordo Judiciário entre Portugal e S. Tomé e Príncipe, de 5 de Julho de 1976; Acordo de Cooperação Jurídica entre a República Portuguesa e a República da Guiné-Bissau, de 5 de Julho de 1988; Acordo de Cooperação Jurídica e Judiciária ente a República Portuguesa e a República Popular de Moçambique, de 12 de Abril de 1990; Acordo de Cooperação Jurídica e Judiciária entre a República Portuguesa e a República de Angola, de 30 de agosto de 1995; Acordo de Cooperação Jurídica e Judiciária entre a República Portuguesa e a República de Cabo Verde, de 2 de dezembro de 2003.

15 Publicada no Diário da República, I Série, de 15 de fevereiro de 2005. 
países ao Tribunal do outro. No entanto, na prática, há entidades nacionais que são chamadas à respectiva tramitação: o Tribunal Supremo, no caso de Angola; o Ministério da Justiça no caso de Moçambique, Guiné-Bissau e S. Tomé e Príncipe; e como já se disse, a Procuradoria-Geral da República de Cabo Verde. Assim, apesar do circuito previsto nos instrumentos internacionais ser directo, os circuitos praticados não diferem do que é habitual, ou seja: Tribunal requerente; Entidade requerente; Entidade requerida; Tribunal requerido.

Se se tratar de actos praticados por agentes diplomáticos e consulares, é expedida carta precatória para a sua prática, remetida a um Cônsul ou Agentes Diplomáticos do Estado requerente sediados no Estado requerido.

\section{Considerações finais}

Apesar de a lei processual portuguesa consagrar um regime de comunicações para obtenção de prova estrangeiro que assenta num modelo clássico, este tem carácter subsidiário face aos regulamentos europeus e aos acordos e tratados internacionais.

No espaço europeu de justiça, o regime de obtenção de prova está consolidado e tende a evoluir, especialmente com a aplicação de meios tecnológicos. Na produção de prova, é notório que a videoconferência será a ferramenta do futuro. Por isso, é indispensável que os tribunais e as vias diplomáticas e consulares possuam os equipamentos e os meios técnicos que proporcionem a efectiva produção de prova da forma mais célere e eficaz, sem diminuição das garantias das Partes, devendo ser adoptadas as mais modernas práticas ${ }^{16}$.

Fora do espaço europeu, as dificuldades agravam-se e a morosidade na obtenção de repostas sobre a execução dos pedidos é o ponto mais frágil. A criação do atlas judiciário e o desenvolvimento da Rede de Cooperação Jurídica e Judiciária Internacional dos Países de Língua Portuguesa contribuirá muito positivamente. Mas falta todo um trabalho de compatibilização dos instrumentos legais de cooperação com as novas práticas.

Não há dúvida dos progressos e do sério propósito de agilização do modelo e das práticas. Isso promoverá a tendencial estabilidade social, económica e política dos países. Porém, à presente data, ainda são muitas as dificuldades em fazer cumprir um pedido transfronteiriço, por cuja execução se pode aguardar muito tempo. É imperioso investir em recursos e nos meios necessários para operacionalizar os pedidos, com vista a uma maior agilidade das comunicações. Só assim os Estados cumprem a sua função de administração da justiça e promovem o acesso à justiça.

16 Cfr., a este propósito, as Recomendações do Conselho para «Promover a utilização e a partilha de boas práticas sobre a videoconferência transfronteiras no domínio da justiça nos Estados-Membros e a nível da UE», JO C 250, de 31.7.2015. 